Морозова А.В.

\title{
Особенности восприятия испанской живописи в России первой половины - середины XIX века
}

\begin{abstract}
Аннотация: Предметом исследования является приходящийся на первую половину - середину XIX в. начальный этап активного знакомства русских зрителей с испанским искусством. Этот этап очень важен, так как именно тогда закладывались основные подходы к испанской живописи в формирующемся российском искусствознании. Автор анализирует оценки и восприятие испанского искусства со стороны литераторов, художников и первых ученых-искусствоведов. Из литераторов выбран В. П. Боткин, из художников К. П. Брюллов, из ученых - А. И. Сомов. Метод исследования состоит в сравнении оценок старой испанской живописи у разных авторов: представителей литературных кругов, художников и первых представителей формирующегося российского искусствознания. Основным выводом проведенного исследования является вывод о дискретности в изучении образов испанского искусства и его стилистики. В трудах такого крупного исследователя искусства, каким являлся А. И. Сомов, соединивший в своих исследованиях образно-эстетический и художественный подходы, чувствуется восхищение образной стороной испанской живописи и неудовлетворенность ее стилистическими особенностями. Понимания неразрывной связи одного с другим еще не было в русской науке об испанском искусстве этого времени.
\end{abstract}

Ключевые слова: Испанское искусство, стилистика, образный строй, Веласкес, Мурильо, Рибера, Сурбаран, Сомов, Боткин, Брюллов.

Review: The subject of the research is the first stage in the active acquaintance of the Russian audience with Spanish art during the first half-the middle of the 19th century. According to the author of the article, this is a very important period because it was the time when the main approaches of Russian art studies to Spanish painting developed. The author analyzes responses and perception of Spanish art by Russian writers, artists and first scholars in art history. Writers discussed by the author are Botkin and Brullov and a scholar is Somov. The research method used by the author of the article involves comparison of evaluations of Spanish painting demonstrated by different people, representatives of literary groups, artists and the first representatives of new Russian art studies. The main conclusion of the research is that studies of Spanish images and styles were rather discrete. A major art critic Somov, for example, whose researches combined aesthetical and artistical approaches, expressed his admiration by the imaginary side of Spanish painting and dissatisfaction of its stylistic patterns. Evidently, Russian science was still to come to understanding that there was an inextricable connection between the former and the latter in Spanish painting of that time.

Keywords: Zurbaran, Ribera, Murillo, Velazquez, images, style, Spanish art, Somov, Botkin, Brullov.

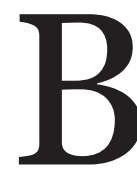

Европе испанская живопись XVII в. долго оставалась практически не известна. Европейцы получили возможность познакомиться с художественными сокровищами Испании в собственно европейских коллекциях только после испанской компании Наполеона. В последующие годы политической нестабильности Испании продолжался вывоз из страны ее живописи.

Одними из первых с восхищением восприняли испанское искусство европейские романтики. Европейский романтизм оказал большое влияние на русскую культуру. Как романтик Испанией и ее искусством был покорен Василий Петрович Боткин (1811-1969).
В. П. Боткин был человеком разносторонне образованным, был близок к литературным кругам. Ему принадлежат одни из первых в едва зарождающемся российском искусствоведении высказываний об испанском искусстве, содержащиеся в его «Письмах об Испании» (впервые были опубликованы в журнале «Современник» в 1847-1851 гг., отдельной книгой вышли в свет в 1857 г.). Как и находящиеся под гипнозом эстетики романтизма немецкие авторы, например историк искусства Ф. Куглер, В. П. Боткин считает, что «два предмета остались испанским художникам - природа и религия» $[1$, с. 70$]$. Природа, по мнению В. П. Боткина, нашла воплощение в творче- 
стве Веласкеса. По справедливому замечанию Х. Лопеса Круса, В. П. Боткин был первым отечественным критиком, благосклонно высказавшимся в пользу Веласкеса [2, с. 45]. До него с восхищением отзывались только о Мурильо. Историко-мифологические полотна Веласкеса (мало известные и в Европе) В. П. Боткин, однако, обходит молчанием. Иллюстрацией же религиозности испанцев, по мнению Василия Петровича, может служить творчество таких мастеров, как Сурбаран и Мурильо. Картины Сурбарана он воспринимает как мрачные и зловещие. «...и гробовая, мертвящая сторона католицизма нашла себе также великого представителя - это мрачный Сурбаран. Он писал одних кающихся монахов: что это за зловещие образы!» $[1$, с. 71$]$ В Мурильо же «...воплотилась страстная, любящая, поэтическая сторона католицизма... Никогда поэзия более мистическая ...не являлась на полотне в такой яркой действительности, облеченная в такую живую форму, доступную самому простому смыслу» $[1$, с. 70$],-$ восторженно писал В. П. Боткин. Рибера в «Письмах...» В. П. Боткина еще не фигурирует. В. П. Боткина интересует прежде всего образно-тематический строй испанской живописи, а не проблемы формы и колорита.

Общеевропейский интерес к испанской культуре и испанской живописи способствовал пополнению испанской части эрмитажного собрания [3, с. 150-151]. Ядро этой «самой значительной за пределами Пиренейского полуострова» галереи испанской живописи [4, с. 22] как доказывает в своих исследованиях Л. Л. Каганэ [5], сформировалось именно в первой половине XIX столетия [3, с. 150; 4, с. 21]. Картины старых испанских мастеров пополнили в первой половине XIX в. и другие российские коллекции [5; 6].

B первой половине XIX в. чрезвычайно окрепла установившаяся еще в XVIII столетии связь русских живописцев с российскими художественными собраниями [3, с. 167]. И испанские картины этих собраний не остались ими не замечены. Особенно в этом отношении выделялся К. П. Брюллов (1799-1852), любимым мастером которого, наряду с другими великими творцами, был Мурильо [7, с. 62]. Наиболее же высоко из всех испанских, да, возможно, и не только испанских художников, Брюллов ставил Веласкеса [7]. Пожалуй, первым в России он обратил внимание на необычную художественную манеру Веласкеса, выражающуюся в особой живописности его мазка («сочность живописи»). Ему нравились веласкесовская «лепка» фигур и его «правда колорита». Рибера и Сурбаран Брюллова не увлекают. Выделение именно Веласкеса из всей испанской школы будет традиционным (хотя потеряет свою исключительность) и для художественных и культурных кругов России второй половины XIX - начала XX в.

Любопытно, что, ставя портретную живопись Веласкеса на недосягаемую высоту, К. П. Брюллов, как и В. П. Боткин, недооценивал его историко-мифологические полотна. По свидетельству его учеников, К. П. Брюллов вторил Ф. А. Бруни, утверждая, что «... он [Веласкес] в картинах совсем не тот, что в портретах...» [7, с. 223] «Веласкес никогда бы не подумал перенести зрителя в мифологический век и непременно бы намарал казенный пейзаж с серым небом. Представить богов он также был не в состоянии, и написал бы просто натурщиков; но натурщиков он написал бы хорошо!» [7, с. 223] - говорил Брюллов. Таким образом, в мифологических полотнах Веласкеса он не видел ничего, кроме «казенного пейзажа» и хорошо написанных «натурщиков». Более глубокое понимание сюжетных полотен Веласкеса придет к представителям русской художественной культуры лишь на рубеже XIX-XX веков.

К. П. Брюллов был в Испании во время заграничной поездки 1849-1852 гг. [7, с. 242] Он отправился в Испанию 23 мая 1850 г. [2, c. 55], побывал в Барселоне, Мадриде, Кадиксе, Севилье. В Барселоне Брюллов написал религиозную «Процессию слепых в Барселоне» (1850-1852 гг.) [8, илл. 218] (Бумага, масло 17,5 x 20,5, Милан, Галерея нового искусства). Других живописных свидетельств его пребывания в Испании нам не известно. Видимо, у Брюллова культура Испании еще не вызывает такого пристального интереса, как это опятьтаки будет свойственно русским живописцам рубежа XIX-XX вв. Любопытно сделанное им во время путешествия на судне вдоль берегов Испании замечание, в котором чувствуется предпочтение, отдаваемое Италии: «...Кажется, Италия как будто сработана Вулканами со всем их знанием и любовью, а Гишпания только эхо или отпрыск...» [9, с. 268]

Другой, уже упомянутый выше в связи с Брюлловым и Веласкесом, крупный русский художник эпохи романтизма - Федор Антонович Бруни (1799-1875). Будучи начальником ведавшего живописью второго отделения Эрмитажа, он купил для эрмитажной коллекции 
целый ряд первоклассных испанских полотен на аукционе картин голландского короля в Гааге и на парижском аукционе картин из коллекции фельдмаршала Сульта [10, с. 180].

В своем увлечении испанцами в первой половине - середине XIX в. Брюллов и Бруни оставались в русском искусстве не одиноки [2, c. 48]. Но все же интерес к коллекционированию испанской живописи в Европе и России и интерес к испанской культуре и испанской литературе шел впереди интереса современных художественных кругов к стилю испанских художников.

Как отмечала Е. О. Ваганова, в России «... обращение к испанскому материалу.. имело не активный, а пассивный характер...» [11, с. 40] Первоклассная эрмитажная коллекция испанской живописи сама по себе, естественно, диктовала обращение к истории испанского искусства. «...сам тип каталогов и путеводителей по Эрмитажу... предусматривал в числе других посвященные Испании разделы» [11]. Первый путеводитель по картинной галерее Эрмитажа был написан А. И. Сомовым и издан в 1859 г. В нем содержится по существу первый протонаучный обзор испанского искусства. Андрей Иванович Сомов (1830-1909) был старшим хранителем отделения живописи, гравюр и рисунков Императорского Эрмитажа. По образованию математик, он активно самосовершенствовался в области истории искусства, хорошо знал собрания иностранных музеев. А. И. Сомов учился рисованию и сам был гравером. Он был близок к художественным кругам Петербурга. И это несомненно повлияло на формирование его методики анализа произведений искусства. В предисловии к своему путеводителю А. И. Сомов замечает, что «... имел в виду не только сообщить некоторые сведения о картинах, составляющих Әрмитажную коллекцию, но также вкратце познакомить посетителей ея с историей живописи и с характером главнейших направлений этого искусства» $[12$, с. 5]. Из важнейших источников относительно истории испанского искусства он называет «Исторический словарь» Сеана Бермудеса [13]. Таким образом, его труд представляет собой ставший характерным для последующих путеводителей жанр краткой истории искусства, проиллюстрированной примерами из состава эрмитажной коллекции. А. И. Сомов надеялся, что его, как он пишет, «посильный труд» вознаградит отсутствие всякого «руководителя» по залам Императорского Әрмитажа. Дело в том, что с февраля 1852 г. Әрми- таж стал публичным музеем, что потребовало издания путеводителя, и осуществленного А. И. Сомовым на достаточно высоком научном уровне, который будет свойственен и всем последующим изданиям такого рода. А. И. Сомов сдержан в своих оценках. Он далек и от экзальтированного восхищения и от огульного поругания, что само по себе свидетельствует о зарождении научного подхода. Заслуживает внимания, что А. И. Сомов не дискриминирует Риберу и Сурбарана и не превозносит преувеличенно Мурильо, как это будет свойственно популярным историям искусства. Ранг жанра путеводителя по императорскому собранию диктовал свой стиль изложения, далеко не характерный даже для многих современных историй искусства. В творчестве почти всех испанских мастеров А. И. Сомов находит как позитивные, так и негативные моменты. Так, он высоко оценивает Луиса Моралеса. Он пишет: «Луис Моралес..., увенчанный в Испании тем же именем, каким всеобщий восторг величал Рафаэля..., действительно, достоин называться божественным за глубокое чувство, сияющее во всех его картинах. Выражение святости, душевной скорби и религиозного восторга - его отличительные качества» [11, с. 61-62]. Но в то же время он отмечает, что рисунок его «весьма неправилен, а кисть суха». Портрет поэта де Эрсильи Эль Греко он назвал «выразительным», но не преминул заметить, что «... Грек, усовершенствовавшись в школе Тициана, основал в Толедо свою школу, где, чтобы быть оригинальным, впал в уродливость и ложь рисунка» [11, с. 61-62]. Риберу хвалит за «могущество ...кисти», отмечает «смелость и новизну», с которыми он изображал «мучения, казни и слезы», а стиль «Св. Себастьяна» этого мастера называет «полным вкуса и благородства». Но произведения Риберы, считает А. И. Сомов, «приличнее было бы поместить в залах итальянской живописи», поскольку он «...провел почти всю жизнь свою в Италии» [11, с. 64] и учился у Караваджо. Сурбаран ему нравится «искусством соразмерять силу тонов с планами», верным рисунком, широкими драпировками, простой и «глубоко обдуманной» композицией. Но он находит, что одно у Сурбарана все же заслуживает упрека - это его «пасмурность колорита». Веласкес - «...один из числа величайших художников всех времен. Колорит его гармоничен, полон изучения, богат и точен, рисунок - изящен и свободен. В портретной живописи с Веласкесом могут сравняться только Тициан и Рубенс - и то 
не всегда» [11, с. 66-67]. Об эскизе к портрету Иннокентия X, входившем в те годы в состав эрмитажной коллекции, А. И. Сомов пишет: «нельзя не остановиться перед ним в восторге от живости красок, смелости кисти и рельефности...» Мурильо, по мнению А. И. Сомова, «лучший и известнейший из испанских живописцев...» Но в его творчестве чувствуется пренебрежение рисунком. Хвалит А. И. Сомов и Алонсо Кано за «нежность... кисти», владение «полутонами и музыкой колорита», святость и простоту его церковных произведений, верность рисунка и очаровательное выражение лиц.

Таким образом, в этом путеводителе А. И. Сомова практически впервые в России, если не учитывать искусствоведческие описания В. П. Боткина, растворяющиеся в более широком по интересам общем контексте его писем, вводится в научный оборот творчество целой плеяды испанских живописцев Золотого века. Как мы убедились, А. И. Сомов старается быть беспристрастным. Только творчество Веласкеса он оценивает «высшим баллом». В творчестве почти всех других мастеров А. И. Сомов находит плохое и хорошее с точки зрения современного ему художественного вкуса. Но выразительность испанских полотен его не оставила равнодушным. Он еще не ставит перед собой цели выявить внутреннюю линию эволюции испанской живописи. Он характеризует испанскую школу живописи в целом, подчеркивая ее самобытный характер, обусловленный, по его мнению, вполне в духе позитивизма, характером природы Иберии и испанской историей. Он пишет: «В каком бы месте Пиренейского полуострова не происходила деятельность художника, характер его живописи носит отпечаток, общий всем испанцам - строгий, суровый, идеальный..., с колоритом сильным и теплым, как небеса Андалузии и Валенсии, с рисунком грандиозным, как природа полуострова, с выражением печально-благочестивым, как дух народа, над которым тяготела инквизиция» [11, с. 60].

Таким образом, выделяются такие для А. И. Сомова самостоятельно существующие стороны искусства, как настроение, колорит, рисунок. Настроение испанских полотен его подкупает. Колорит часто очаровывает, а рисунок, по его мнению, оставляет желать лучшего.

Как мы видим, выявляется несколько подходов к старой испанской живописи в русском обществе середины XIX в.: образно-сюжетный и литературный, представителем которого был В. П. Боткин, художественно-эстетический, представленный главным образом К. П. Брюлловым, и собственно протонаучный в лице А. И. Сомова. Пристальное внимание последнего к художественному языку испанцев соединялось со стремлением почувствовать настроение испанских полотен и понять их образный строй. Но если образы испанских полотен подкупают А. И. Сомова своей выразительностью, то испанская стилистика удовлетворяет его далеко не всегда. Эта дифференциация и дискретность в изучении образов и стилистики сохранится в России и в последующем. Только на рубеже XIX-XX вв. авторы сделают попытку выявить пластическую идею произведения, что даст возможность вкупе рассмотреть выразительность образов и стилистику полотен и обеспечит полную реабилитацию всего испанского искусства XVII в.

\section{Библиография:}

1. Боткин В. П. Письма об Испании. Л.: Наука, 1976. 343 с.

2. Лопес Крус X. Мурильо и Веласкес в русской художественной культуре XIX — начала XX веков. Диссертация на соискание ученой степени канд. Искусствоведения. Рукопись. М., 2001. 312 с.

3. Левинсон-Лессинг В. Ф. История Картинной галереи Эрмитажа (1764-1917). Л.: Искусство, 1985. $408 \mathrm{c}$.

4. Каганэ Л. Л. Испанская живопись XVII - начала XIX века. История собрания и его состав // Spanish Art of the XVI-XIX Centuries from State Hermitage Museum. Edites and Published by Committee for the Exhibition of The State Hermitage Museum. St. Petersburg, 1996. P. 8-33.

5. Каганэ Л. Л. Испанская живопись в Эрмитаже. XV - начало XIX в. История собрания. La pintura española del Museo del Ermitage. Siglos XV á comienzos del XIX. Historia de una colección. Traducción : Aquilino Duque (en español y ruso). СПб.; Севилья, Фонд Эль Монте: Изв-во Гос. Эрмитажа, 2005. 602 с.

6. Каганэ Л.Л. Картины старых испанских мастеров в частных собраниях Санкт-Петербурга. Конец XVIIIначало XX века. СПб.: Изд-во Государственного Эрмитажа, 2014. 408 с. 
7. К. П. Брюллов в письмах, документах и воспоминаниях современников. Составитель книги и автор предисловия проф. Н. Г. Машковцев. Изд. 2-е, доп. М.: Изд-во Академии художеств СССР, 1961. 318 с.

8. Карл Брюллов. Альбом. Автор-составитель М.М. Ракова. М., Изобразительное искусство, 1988. 47 с. текста, 228 илл.

9. Мастера искусства об искусстве. Избранные отрывки из писем, дневников, речей и трактатов. В 7-ми т. Под общей ред. А. А. Губера и др. М., «Искусство», 1965-1970. Т. 6. Искусство народов CCCP XIVХІХ вв. Под ред. А. А. Федорова-Давыдова. 1969. 543 с. , 41 л. илл.

10. Верещагина А. Г. Федор Антонович Бруни. Л.: Художник РСФСР, 1985. 255 с. с илл.

11. Ваганова Е.О. Советское искусствознание об испанских живописцах эпохи расцвета // Проблемы искусствознания и художественной критики. Межвузовский сборник. Под ред. Т. В. Ильиной, Н. Н. Калитиной, В. А. Суслова. Л.: Изд-во Ленинградского университета, 1982. С. 37-50.

12. Сомов А. И. Картины императорского Эрмитажа. СПб., изд-во не указано, 1859, 179 с.

13. Diccionário histórico de los más ilustres profesores de las bellas artes en España, por D.I.A.C. Bermúdez. Madrid, 1800. T. 1-6.

\section{References (transliterated):}

1. Botkin V. P. Pis'ma ob Ispanii. L.: Nauka, 1976. $343 \mathrm{~s}$.

2. Lopes Krus Kh. Muril'o i Velaskes v russkoi khudozhestvennoi kul'ture XIX — nachala XX vekov. Dissertatsiya na soiskanie uchenoi stepeni kand. Iskusstvovedeniya. Rukopis'. M., 2001. 312 s.

3. Levinson-Lessing V. F. Istoriya Kartinnoi galerei Ermitazha (1764-1917). L.: Iskusstvo, 1985. 408 c.

4. Kagane L. L. Ispanskaya zhivopis' XVII - nachala XIX veka. Istoriya sobraniya i ego sostav // Spanish Art of the XVI-XIX Centuries from State Hermitage Museum. Edites and Published by Committee for the Exhibition of The State Hermitage Museum. St. Petersburg, 1996. P. 8-33.

5. Kagane L. L. Ispanskaya zhivopis' $v$ Ermitazhe. XV - nachalo XIX v. Istoriya sobraniya. La pintura española del Museo del Ermitage. Siglos XV á comienzos del XIX. Historia de una colección. Traducción : Aquilino Duque (en español y ruso). SPb.; Sevil'ya, Fond El' Monte: Izv-vo Gos. Ermitazha, 2005. 602 s.

6. Kagane L.L. Kartiny starykh ispanskikh masterov v chastnykh sobraniyakh Sankt-Peterburga. Konets XVIIInachalo XX veka. SPb.: Izd-vo Gosudarstvennogo Ermitazha, 2014. 408 s.

7. K. P. Bryullov v pis'makh, dokumentakh i vospominaniyakh sovremennikov. Sostavitel' knigi i avtor predisloviya prof. N. G. Mashkovtsev. Izd. 2-e, dop. M.: Izd-vo Akademii khudozhestv SSSR, 1961. 318 c.

8. Karl Bryullov. Al'bom. Avtor-sostavitel' M.M. Rakova. M., Izobrazitel'noe iskusstvo, 1988. 47 s. teksta, 228 ill.

9. Mastera iskusstva ob iskusstve. Izbrannye otryvki iz pisem, dnevnikov, rechei i traktatov. V 7-mi t. Pod obshchei red. A. A. Gubera i dr. M., «Iskusstvo», 1965-1970. T. 6. Iskusstvo narodov SSSR XIV-XIX vv. Pod red. A. A. FedorovaDavydova. 1969. 543 s. , 41 1. ill.

10. Vereshchagina A. G. Fedor Antonovich Bruni. L.: Khudozhnik RSFSR, 1985. 255 s. s ill.

11. Vaganova E.O. Sovetskoe iskusstvoznanie ob ispanskikh zhivopistsakh epokhi rastsveta // Problemy iskusstvoznaniya i khudozhestvennoi kritiki. Mezhvuzovskii sbornik. Pod red. T. V. Il'inoi, N. N. Kalitinoi, V. A. Suslova. L.: Izd-vo Leningradskogo universiteta, 1982. S. 37-50.

12. Somov A. I. Kartiny imperatorskogo Ermitazha. SPb., izd-vo ne ukazano, 1859, 179 s.

13. Diccionário histórico de los más ilustres profesores de las bellas artes en España, por D.I.A.C. Bermúdez. Madrid, 1800. T. 1-6. 